\title{
Literatura e estilo em Minha Formação, de Joaquim Nabuco ${ }^{1}$
}

\author{
Marcus Vinicius de Freitas \\ Universidade Federal de Minas Gerais
}

\begin{abstract}
Resumo: Este artigo investiga o conceito de literatura desenvolvido por Joaquim Nabuco em seu livro de memórias, Minha formação, com dois objetivos: em primeiro lugar, a análise possibilita uma compreensão metacrítica do conjunto da obra de Nabuco, que se caracteriza por uma escrita marcada por estilo próprio, de grande clareza e eficiência interpretativa; por outro lado, a investigação do seu conceito de literatura leva a uma reflexão sobre a mentalidade literária de sua geração, que se inicia na fase final do romantismo e percorre o tempo do nosso primeiro realismo.
\end{abstract}

Palavras-chave: Joaquim Nabuco, Memórias, Literatura, Estilo.

Joaquim Nabuco publicou seu livro de memórias, Minha formação, em 1900, aos 51 anos de idade, reunindo material que havia sido publicado em 1895 no Diário do Comércio de São Paulo e posteriormente na Revista Brasileira, aos quais foram acrescentados textos, emendas e variantes produzidos até 1899. No todo, diz o autor, o texto deveria ser lido com o olhar nos anos que vão de 1893 a 1899. Nessa época, Nabuco já se retirara da política. Esses são os mesmos seis

1. Este texto faz parte do projeto "O escritor e seu ofício", financiado pela Bolsa de Produtividade em Pesquisa do CNPq. 
anos da meditação sobre o império, através da escrita de Um estadista do império, biografia de seu pai, Nabuco de Araújo, cuja vida é ali tomada como fio condutor de uma análise ampla e lúcida da sociedade brasileira no período monárquico.

O espírito de balanço desses dois textos, a biografia do pai e as memórias do filho, mesmo para um homem ainda muito jovem, revela-se esclarecedor quando nos dirigimos às observações de Nabuco sobre literatura, a contraface de sua paixão pela política. É o próprio memorialista quem diz:

Desde a Academia a literatura e a política alternaram uma com a outra, ocupando a minha curiosidade e governando as minhas ambições. Nos primeiros anos a política teve o predomínio; com a viagem à Europa em 1873 passou este para a literatura, e esse meu período literário, começado então, dura até 1879 , quando entro para a Câmara. ${ }^{2}$

Da Academia, duas figuras suas contemporâneas são relembradas com destaque nas memórias: Castro Alves e Rui Barbosa, como a representar aquelas duas facetas da sua ambição. ${ }^{3}$ No caso de Castro Alves, cabe destacar que o poeta do "Navio Negreiro" incorpora à faceta literária a dimensão política do antiescravagismo, tema central da atuação pública de Nabuco, aparecendo portanto como uma espécie de imagem ideal do autor de Minha formação.

Investigar as considerações de Joaquim Nabuco sobre literatura, no texto de auto-análise que é Minha formação, constitui então uma tarefa de duplo interesse: por uma lado, possibilita uma compreensão metacrítica do conjunto da obra de Nabuco, obra essa que se caracteriza por uma escrita marcada por estilo próprio, de grande clareza e eficiência interpretativa, como demonstram os comentários sobre Um estadista do império emitidos por tão variados críticos, tais como os nossos contemporâneos Evaldo Cabral de Melo, Raymundo Faoro ou João Camilo de Oliveira Torres, ou contemporâneos de Nabuco, tais como Machado de Assis e José Veríssimo; ${ }^{4}$

2. NABUCO. Minha formação, p. 54.

3. Ver NABUCO. Minha formação, p. 6.

4. Para os juízos sobre o estilo e a escrita historiográfica de Nabuco, ver, entre outras fontes, a perigrafia da 5 a edição da obra referida. Sobre o estilo historiográfico de Nabuco, cabe lembrar, a título de exemplo, as palavras introdutórias de Raymundo Faoro para essa edição: "A história visceralmente artística, que Joaquim Nabuco (1849-1910) evoca, não obedece a leis, no sentido que lhe dão as ciências naturais, nem a regras 
por outro lado, possibilita a análise intrínseca do seu conceito de literatura, o que se reveste, em boa medida, de uma reflexão sobre a mentalidade literária de sua geração, que se inicia na fase final do romantismo e percorre o tempo do nosso primeiro realismo, às vezes se deixando tocar pela "idéia nova", às vezes mantendose fiel ao ideário romântico.

No capítulo VII de Minha formação, Nabuco constrói uma síntese do seu panteão historiográfico e crítico-literário:

Em crítica literária, achava-me todo imbuído de Sainte-Beuve, Taine, Scherer, ainda que deste último, de quem falarei, não tanto como depois que o conheci. Em poesia, tinha passado de Lamartine para Victor Hugo, o de Hernani quase exclusivamente, e de V. Hugo para Musset, como devia depois passar de Musset para Shelley, de Shelley para Goethe, escala em que parei, mas onde não espero morrer, porque tenho diante de mim o Dante..., o que não quer dizer que não tenha nos ouvidos a ressonância das grandes rimas novas de um Banville, e não admire o cinzelado dos fortes relevos de José-Maria Heredia. Em prosa, Chateaubriand e Renan dividiam o império com Cícero, cujas cartas são talvez o livro mundano que eu levaria comigo, se tivesse que ficar encerrado em uma ilha deserta. A frase, a eloqüência, o retrato e a encenação histórica de Macaulay foi também uma influência permanente que se imprimiu em meu espírito; hoje eu teria que acrescentar Mommsen, Curtius, Ranke, Taine, Burkhardt. Quanto ao romance, que é a imaginação abrangendo e modelando a vida, eu ficara sob a impressão de Jules Sandeau; vivia à sombra dos seus castelos antigos reconstruídos pela moderna burguesia entre as duas sociedades, a velha e a nova, que ele queria fundir pelo amor, e mais que a poesia d'alma de Sandeau, que foi muito grande e a que ainda um dia a França há de voltar, era para mim indefinível a impressão, aristocrática e feminina a um tempo, dos últimos encantadores estudos de Cousin sobre a sociedade do século XVII.

prefixadas, que prenunciem os acontecimentos. Cultivou-a como uma ciência cultural, longe do positivismo dominante no seu tempo, que reduziria todo o conhecimento a constantes previsíveis e inexoráveis." (FAORO. História e arte, p. 21). Sobre a eficiência e a originalidade de sua interpretação da história, lembro o comentário de Evaldo Cabral de Melo: "Nabuco foi o primeiro a articular numa visão da sociedade brasileira a intuição segundo a qual o regime servil é a variante sociológica que a explica de maneira mais abrangente." (MELO. Um livro elitista?, p. 1324). 
Tudo isto formava o fundo do meu espírito, o húmus da minha inteligência, quando começou a fase literária, aquela em que senti uma impulsão interior irresistível para entrar na literatura. O período anterior de receptividade, de plantio, de assimilações; a impressão, o prazer maior era o de ler; agora, vinha a necessidade de produzir, de criar, e dava-se um fato singular, resultado desses anos de leituras francesas: eu lia muito pouco o português, ainda não começara a ler o inglês e desaprendera o alemão da Maria Stuart e de Wallenstein, com verdadeira mágoa do meu velho mestre Goldschmidt. O resultado foi que me senti solicitado, coagido pela espontaneidade própria do pensamento, a escrever em francês.

Cabe destacar, no trecho citado, o paralelo entre o percurso das influências historiográficas e o das afinidades crítico-literárias. Em ambos os casos, o caminho das leituras de Nabuco está centrado nos franceses, mirando os alemães, e acertando nos ingleses.

Em crítica literária, seu percurso se restringe basicamente a SainteBeuve, ${ }^{6}$ Taine ${ }^{7}$ e Scherer. ${ }^{8}$ Quando se trata de poesia, as referências evoluem de Lamartine, ${ }^{9}$ Victor Hugo, ${ }^{10}$ Musset ${ }^{11}$ e Banville ${ }^{12}$ para Shelley ${ }^{13}$ e depois para

5. NABUCO. Minha formação, p. 55-56.

6. Charles Augustin Sainte-Beuve (1804-1869); importante crítico literário francês, praticante da crítica biográfica, posteriormente muito criticado por Marcel Proust em sua defesa de uma crítica imanente da obra literária.

7. Hippolyte Taine (1828-1893); crítico e historiador francês, o mais destacado praticante da crítica positivista do século XIX.

8. Edmond Schérer (1815-1889); crítico literário francês, que não deve ser confundido com Wilhelm Scherer, escritor, filólogo e historiador da literatura alemão.

9. Alphonse de Lamartine (1790-1869), poeta romântico francês, de grande influência sobre os românticos brasileiros.

10. Victor Hugo (1802-1885); o maior poeta e romancista romântico francês, idolatrado em vida não apenas na França, mas em todos os países onde chegou a influência da cultura francesa.

11. Alfred de Musset (1810-1857); destacado poeta romântico francês, cuja poesia sentimental constitui expressão acabada do romantismo.

12. Theodore de Banville (1823-1891), poeta francês muito marcado pela eloquência de Victor Hugo.

13. Percy Bisshe Shelley (1792-1822); importante poeta da segunda geração romântica inglesa, ao lado de John Keats e de Lord Byron. O poeta foi casado com Mary Shelley, autora do romance gótico Frankenstein. 
Goethe, ${ }^{14}$ mesmo fazendo certa reverência ao parnasianismo de Heredia. ${ }^{15} \mathrm{O}$ mesmo tipo de evolução do pensamento e das afinidades de Nabuco se pode depreender quando o assunto é historiografia. Nesse campo, segue ele de Taine para Macaulay, ${ }^{16}$ e daí a Mommsen, ${ }^{17}$ Curtius, ${ }^{18}$ Ranke ${ }^{19}$ e Burckhardt. ${ }^{20}$ O que se poderia, a princípio, depreender desse percurso seria a lenta ascensão, no pensamento de Joaquim Nabuco, do que Sílvio Romero designaria como germanismo crítico, ou seja, a mudança das influências francesas para as alemãs na crítica brasileira, cujo representante mais acabado seria Tobias Barreto e a sua "escola do Recife". ${ }^{21}$ Em Nabuco, entretanto, a prosa inglesa será a imagem buscada pelo estilista maduro, como poderemos ver mais adiante. Quando ele menciona de passagem que "ainda não começara a ler o inglês" tem-se uma senha para a compreensão do caminho que tomará a sua escrita amadurecida.

14. Wolfgang Goethe (1749-1832); o mais importante escritor da literatura alemã, figura central do romantismo, que ajudou a forjar, através do movimento Sturm und Drang (tempestade e ímpeto).

15. José Maria Heredia (1842-1905); poeta parnasiano francês, publicado no Parnasse Contemporain.

16. Thomas Macaulay (1800-1859); poeta e historiador inglês cujo estilo historiográfico se caracteriza pela narração vívida dos fatos. Raymundo Faoro assim descreve esse historiador e sua ascendência sobre Nabuco: "Hoje, como no seu tempo, quando era imenso o prestígio intelectual que lhe cercou o nome, ninguém lhe nega a energia e a magia da arte de narrar (...) Foi o artista, refugiado no narrador, que seduziu Joaquim Nabuco, conferindo-lhe a ascendência no elenco de suas afinidades." (FAORO. História e arte, p. 23).

17. Theodor Mommsen (1817-1903); historiador alemão, especialista em história romana, que recebeu o Prêmio Nobel de Literatura em 1902.

18. Ernst Curtius (1814-1896); historiador e arqueólogo alemão, especialista em história e cultura grega.

19. Leopold von Ranke (1795-1886); destacado historiador alemão do século XIX, cuja maior contribuição aos estudos históricos está na importância dada ao uso das fontes.

20. Jacob Burckhardt (1818-1897); de origem suíça, Burckhardt se notabilizou como historiador da arte, em especial do Renascimento. De perfil conservador, sua obra se caracteriza, como destaca Oto Maria Carpeaux, pelo traço conservador e defensor da civilização européia. Ver CARPEAUX. A cinza do purgatório.

21. Ver ROMERO. História da literatura brasileira, 5ํv., p. 1813. 
$\operatorname{Renan}^{22}$ aparece como a referência maior de prosador e de homem de cultura para o jovem Nabuco, ao lado da matriz clássica de Cícero ${ }^{23}$ e novamente da francesa com Chateaubriand. ${ }^{24}$ Da mesma maneira, no caso do romance, a sua admiração se volta para um francês, Jules Sandeau. ${ }^{25}$

Diante dessa série de nomes e de influências, sobretudo as marcas francesas das leituras de juventude, não é de se estranhar que o autor confesse ter despertado para a escrita de poesia através da língua francesa, que se tornou o seu instrumento poético em detrimento do português, no qual ele lia muito pouco. Trata-se de um caso radical de colonização por uma cultura estrangeira através da língua, ainda que para Nabuco aquele galicismo assumido fosse tomado como signo universalizante, o que mais reforça sua dedicação à cultura francesa. A paixão pela língua e pela literatura francesas levaram-no a escrever e publicar o livro Amour et Dieu, em que os motivos e as soluções poéticas, estando, totalmente embebidos da matriz literária, não apresentavam qualquer novidade, qualquer originalidade ou valor permanente, como o próprio memorialista aponta de maneira lucida e crítica nas suas memórias.

Aquele panteão demonstra igualmente que Nabuco, mesmo tendo nascido em 1849 e morrido em 1910 - e sendo portanto contemporâneo da American Renaissance - foi ao longo de sua vida pouco tocado pelas influências literárias e culturais norte-americanas, ainda que revele grande admiração pela civilização material da nação do norte, onde morou por um ano. Comentando nas memórias o diário que escreveu em 1877, quando de sua estadia nos EUA, Nabuco recupera de suas observações a afirmação de que, estando em Nova York, "não se achava sob influência americana, mas (...) continuava em mim a influência

22. Ernest Renan (1823-1892); prosador, filósofo e historiador francês de grande influência na cultura ocidental na segunda metade do século XIX. $\mathrm{Na}$ paisagem brasileira, Nabuco foi dos que mais bebeu nessa fonte, como atesta o fato de que o capítulo de Minha formação de onde sai o trecho citado se chama exatamente "Ernest Renan".

23. Caio Tulio Cícero (106-43 a.C.); filósofo e político romano, notabilizado como orador e como defensor da república, além de grande escritor.

24. François-René de Chateaubriand (1768-1848); romancista francês de grande importância na formação do ideário romântico.

25. Jules Sandeau (1811-1883); dramaturgo e romancista francês de grande apelo popular. 
européia”. ${ }^{26}$ Seu reconhecimento da civilização material americana vem sempre acompanhado pelo desdém em relação à sua vida espiritual e cultural:

Para o engenheiro, para o inventor, para o arquiteto, para todo economizador de tempo e trabalho, para quem admira acima de todos o gênio industrial deste século, os melhoramentos que ele tem introduzido na ferramenta humana, os Estados Unidos são de uma extremidade a outra um país para se visitar e conhecer. É ele, talvez, o país onde melhor se pode estudar a civilização material, onde o poder dinâmico ao serviço do homem parece maior e ao alcance de cada um. Em certo sentido, pode-se dizer dele que é uma torre de Babel bem sucedida. Na ordem intelectual e moral, porém, compreendo a arte, os Estados Unidos não têm o que mostrar, e certa ordem de cultura, toda cultura superior quase não precisa para ser perfeita e completa de adquirir nenhum contingente americano. ${ }^{27}$

A essa recusa intelectual e cultural se associa a sua distância em relação ao governo republicano, consagrado nos EUA, em oposição à sua admiração pela monarquia constitucional da Inglaterra, que, ao longo da vida, foi se estabelecendo para ele como modelo político exemplar, ao lado da crescente influência que o ensaísmo inglês foi tendo sobre seu estilo. A Inglaterra era, no entender de Nabuco, o único país realmente livre do mundo, cuja liberdade estaria sintetizada na equanimidade do sistema judiciário e no consenso do respeito à leis:

A minha passagem pela Inglaterra deixou-me a convicção, que depois se confirmou nos Estados Unidos, de que só há, inabalável e permanente, um grande país livre no mundo (...) Somente na Inglaterra, pode-se dizer, há juizes. ${ }^{28}$

A França, de suas predileções literárias de juventude, constituía para ele igualmente um país livre, mas em cujo espírito a liberdade não estaria arraigada, e sim sempre sujeita a crises revolucionárias. ${ }^{29}$

26. NABUCO. Minha formação, p. 134.

27. NABUCO. Minha formação, p. 136. Grifo meu.

28. NABUCO. Minha formação, p. 100-101.

29. Ver NABUCO. Minha formação, p. 101. 
Dessa forma, mesmo tendo sido contemporâneo dos americanos Whitman, Melville, Hawthorne, Twain, Emerson, Thoreau e Henry James; contemporâneo do realismo e do naturalismo francês; e ainda contemporâneo da revolução estética do simbolismo de Baudelaire, Rimbaud, Verlaine e Mallarmé, Nabuco manteve entretanto um arraigado gosto literário pelo romantismo francês. Mesmo que esse gosto permanecesse até o fim da vida, o reconhecimento de sua falta de vocação poética, com o falhado Amour et Dieu, e o posterior mergulho na vida política parecem ter deixado o romantismo literário preso às memórias de juventude, algo que guardasse como uma relíquia de si próprio, substituído ao longo do tempo por uma estética política adquirida com a historiografia inglesa (o caso de Macaulay), e também com o seu ensaio e sua literatura. A mudança fundamental acontece quando de sua residência na Inglaterra, ainda na década de 1870 . Thackeray seria o ponto de partida, ${ }^{30} \log 0$ seguido por outros autores, que sustentam a sua posição de monarquista liberal:

Eu encontrava republicanismo na Inglaterra em espíritos de primeira ordem; havia republicanismo, mais ou menos consciente, em Spencer, ${ }^{31}$ em Mill, ${ }^{32}$ em Bagehot, ${ }^{33}$ em Bright, ${ }^{34}$ em Morley, ${ }^{35}$ em George Eliot, ${ }^{36}$ em G. Henry Lewes, ${ }^{37}$ mas era republicanismo sine die, conservado no sentimento monárquico, para impedi-lo de corromper-se. ${ }^{38}$

30. "Em mim a conquista anglo-saxônia começou por Thackeray (...)". NABUCO. Minha formação, p. 70.

31. Herbert Spencer (1820-1903); filósofo inglês, que adaptou as idéias de Darwin ao pensamento social e que teve grande repercussão no positivismo brasileiro.

32. John Stuart Mill (1806-1873); filósofo e economista inglês, cujo pensamento foi fundamental na construção do liberalismo.

33. Walter Bagehot (1826-1877); jornalista e ensaísta inglês de grande importância para o pensamento econômico liberal.

34. John Bright (1811-1889); Político e grande orador inglês, intransigente defensor do liberalismo.

35. John Morley (1838-1923); jornalista, escritor e importante político liberal inglês.

36. George Eliot (1819-1880); pseudônimo de Mary Ann Evans, uma das maiores vozes do romance realista inglês.

37. George Henry Lewes (1871-1878); filósofo, crítico e escritor inglês, amante de George Eliot, importante no círculo do realismo vitoriano.

38. NABUCO. Minha formação, p. 105. 
Aquela admiração permanente pelos franceses, que chegou ao ponto da imitação na obra Amour et Dieu, foi modificada pela descoberta da literatura e do ensaísmo liberal inglês, o que levou portanto à crítica diante da própria produção, autocrítica que foi fundamental na conquista de um estilo literário eficiente. No capítulo intitulado "A crise poética", Nabuco mostra que seus versos franceses se erguiam mais como epifenômeno de formas poéticas gastas e de idéias alhures desenvolvidas, do que como trabalho de verdadeira criação. O seu diagnóstico é certeiro: "O que me enganava nos meus versos, parecendo-me sonoro e elevado, não pertencia à poesia, pertenceria à eloqüência." ${ }^{39}$ Mais à frente, ele completa:

Nada é mais contrário à poesia do que a ênfase, o lugar comum e o patético da oratória. Onde começa o advogado ou o tribuno, acaba o poeta. O fato é que não possuo a forma do verso, na qual a idéia se modela por si mesma e donde sai com o timbre próprio da verdadeira rima, que nenhum artifício nem esforço pode imitar. Isto, por um lado, quanto à pequena poesia, à poesia solta, ao que se pode chamar a música da poesia. Quanto à grande poesia, à poesia de imaginação e criação, poema, romance, balada que fosse, para essa eu seria incapaz, além da insuficiência do talento, pela falta de coragem para habitar a região solitária dos espíritos criadores, os quais vivem naturalmente entre figuras tiradas de si mesmos, sem vida própria, autômatos da sua inteligência e da sua vontade, como em um sonho acordado. Nessa altura, onde tudo é fictício, tudo irreal, tudo fantástico, a poesia tem para mim o terror do adytum da Pítia. Mesmo quando as figuras sejam meigas, suaves, humanas, a criação envolve sempre alguma coisa de misterioso e terrível; a completa abstração, que ela supõe, da realidade exterior, do mundo dos sentidos, me daria vertigem. ${ }^{40}$

Mais do que um diagnóstico sobre o próprio talento ou vocação, a passagem nos importa como o desenvolvimento de uma consciência sobre arte e de um conceito sobre literatura. A poesia se opõe à eloquência, seria o mote de Nabuco na passagem. Como não domina essa separação em seu próprio ato criativo (por falta de talento inato, diria ele), rejeita conscientemente a sua poesia, por secundária, e escolhe o caminho da política. Essa autocrítica constitui uma

39. NABUCO. Minha formação, p. 64.

40. NABUCO. Minha formação, p. 64. 
consciência muito aguda quando desenvolvida num ambiente marcado pelo que Luiz Costa Lima denomina de "cultura auditiva", afeita ao púlpito, ao palanque e à tribuna, marcada assim pelas formas superficiais e retóricas de convencimento, em detrimento dos raciocínios encadeados e lógicos. ${ }^{41}$

Da mesma maneira, a prosa também deve se opor à eloquência, diz Nabuco. Essa postura de condenação da nossa tradição eloquente, ainda que aparentemente contraditória em um autor que permanecia admirador de Victor Hugo, leva Nabuco a comentários bastante reveladores sobre a designação corrente de "artista" empregada para descrever muitos dos seus contemporâneos. A passagem sobre Rui Barbosa, figura que ele sinceramente admira, é exemplar:

Muitas vezes tenho lido e ouvido falar de Rui Barbosa como de um artista, pelo modo por que escreve a prosa. No mesmo sentido poderse-ia chamar a Krupp artista: a fundição é de alguma forma uma arte, uma arte ciclópica, e de Rui Barbosa não é exagerado dizer, pelos blocos de idéias que levanta uns sobre outros e pelos raios que funde, que é verdadeiramente um ciclope intelectual. Mas o artista? Existirá nele a camada da arte? Se existe, e é bem natural, ainda jaz desconhecida dele mesmo por baixo das superposições da erudição e das leituras. Eu mesmo já insinuei uma vez: ninguém sabe o diamante que ele nos revelaria, se tivesse a coragem de cortar sem piedade a montanha de luz, cuja grandeza tem ofuscado a República, e de reduzi-la a uma pequena pedra.

A comparação entre Rui e o trabalho de Fritz Krupp - o herdeiro da indústria siderúrgica alemã Krupp no tempo de Nabuco - dá a medida do modo como Joaquim Nabuco considerava a eloquência em arte, consequência de suas leituras anglo-saxônicas. A comparação não consegue conter a ironia, mesmo que busque reconhecer a grandeza de Rui, diamante bruto que mais brilharia se devidamente cortado e lapidado. A imagem advinda da ourivesaria cria o campo semântico para a leitura da nossa literatura como simples adorno adequado ao gosto auditivo dos poetas de palanque. No caso de Rui Barbosa, essa tendência à ornamentação seria digna de lamento, dada a real possibilidade de produção de uma obra genuína, que se perde pelo excesso. Nabuco aplica o mesmo diagnóstico

41. No dizer do autor: "A cultura auditiva é (...) fundamentalmente uma cultura que se transmite sem cadeias demonstrativas." LIMA. Dispersa demanda, p. 17. 
e a mesma metáfora da rocha bruta a José do Patrocínio, que possuiria em suas prosa muitas passagens poéticas, cujo filão entretanto se perde em meio da "rocha política”. Cabe lembrar que a metáfora geológica, aplicada à mistura brasileira de raças, mas ao mesmo tempo servindo de comentário metapoético, aparece pouco depois em Os sertões, de Euclides da Cunha, conforme já demonstrou José Carlos Barreto de Santana, ${ }^{43}$ com a diferença fundamental de que, em Euclides, o estilo é eficiente. Aqui, com certeza, como em toda grande literatura, ele se presta à construção de imagens que veiculam amplos e complexos significados, dos quais a forma não se separa. Por outras palavras, a forma em Euclides é veículo de conteúdo, e por isso seu estilo não redunda em retórica vazia, o mesmo acontecendo com o Nabuco que abdica da poesia em favor da meditação política e histórica. Essa necessidade de conteúdo adequado à forma, advindo do estudo da nossa realidade e de nossa história, constitui em Minha formação um apelo às jovens gerações.

Ao contrário de Rui Barbosa ou de José do Patrocínio, o exemplo acabado de Nabuco para a vocação poética realizada é Bilac, ao lado de Luís Murat e de Constâncio Alves. Entretanto, Nabuco lamenta que eles e outros desperdicem seus talentos na falta de aprofundamento em estudos históricos. Nabuco constrói a defesa dos estudos históricos como fundamento da arte poética e da prosa literária a partir de conselhos que lhe foram dados por Ernest Renan. Entretanto, pondera ele, não seguiu as sugestões do mestre francês senão muito tarde na vida, e por isso seu talento de artista teria sido inutilizado.

Procurando transformar essa experiência em conselho às novas gerações de autores, começa ele por apontar a mesquinhez da matéria sobre que trabalham os nossos homens de letras, para daí passar, como corolário, à decadência dos talentos:

O material em que trabalham os nossos homens de letras são os costumes, a sociedade, quando são romancistas ou dramaturgos; as leituras, quando são críticos, a própria vida ou impressões, quando são poetas. O material preferido é, como se vê, todo ele pouco consistente, efêmero, em parte grosseiro, em parte imprestável ou insuficiente, e assim a produção é quase toda fácil, improvisada, sem trabalho anterior, sem investigação, sem esforço, sem tempo, sem nenhum elemento que revele continuidade,

42. NABUCO. Minha formação, p. 67.

43. Ver capítulo 3 de SANTANA. Ciência e arte. 
ambição. Faltando a disciplina e a emulação de uma especialidade, que acontece? A inteligência contrai o hábito da dissipação, da indolência, do parasitismo; o talento relaxa-se, perde todo o peso específico. Temos por isso uma literatura desocupada; o nosso campo literário é composto de flâneurs. ${ }^{44}$

A flâneurie da nossa literatura, que a torna dispersa e indolente, seria um indicativo do fato mesmo de que a arte e a cultura entre nós no tempo de Nabuco, com raras exceções - e Machado de Assis é uma dessas exceções apontadas pelo autor -, teriam a marca supérflua de atividade postiça, decorativa, beletrista, e talvez por este mesmo motivo fossem tão ligadas à auditividade, à cultura de palanque, pelo seu simples efeito de donaire e de ornamentação bacharelesca.

Cabe fazer aqui um parênteses e lembrar que Bilac, em discurso proferido em 1907, por ocasião da homenagem que recebeu em função dos vinte anos da publicação de seu livro Poesias, aponta esse mesmo mal-estar em relação à gratuidade do ofício de escritor até a sua geração, e completa dizendo que o ato de tornar o ofício social e culturalmente pertinente, através da profissionalização do escritor, teria sido a maior contribuição da mesma geração para as letras brasileiras:

Que fizemos nós? Fizemos isto: transformamos o que era antes um passatempo, um divertimento, naquilo que é hoje uma profissão, um culto, um sacerdócio; estabelecemos um preço para o nosso trabalho, porque fizemos desse trabalho uma necessidade primordial da vida moral e da civilização da nossa terra; forçamos as portas dos jornais e vencemos a inépcia e o medo dos editores. ${ }^{45}$

Bilac, que partiu da mais gratuita das formas de poesia - o parnasianismo da pura forma -, parece ter ouvido os apelos de Nabuco, patente na inflexão que sua obra sofreu pela escrita diária de crônicas em vários veículos, em especial na Gazeta de Notícias, em substituição a Machado de Assis a partir de 1897, crônicas em que, pela verve da pena afiada, passou em revista a nossa sociedade e a nossa cultura. Ao final da vida, Nabuco com certeza concordou com aquela afirmação de Bilac sobre a geração da virada do século, uma vez que entre

44. NABUCO. Minha formação, p. 69-70.

45. BIlaC. In: MaGalHães JúNIOR. Olavo Bilac e sua época, p. 298. 
1893, quando da escrita dos primeiros trechos de Minha formação, e 1907, quando do balanço feito por Bilac, boa parte daquela geração, a exemplo do próprio Bilac, aceitara o apelo de Nabuco por uma literatura de missão, feito com base em seus pressupostos estéticos:

Aconselhar a jovens brasileiros que se dediquem a estudos históricos desinteressados é aconselhar-lhes a miséria; mas as leis da inteligência são inflexíveis e a produção do espírito que não se alimenta senão de sua própria imaginação, tem que ser cada dia mais frívola e sem valor. ${ }^{46}$

Cabe lembrar que, do ponto de vista da intelectualidade que acalentara e apoiara a República, 1893 foi igualmente uma ano de frustração e consequente tomada de consciência sobre os rumos do movimento, em função das ações da ditadura florianista, o que coincide com o início da escrita do grande livro de Nabuco sobre a politica imperial e com a mudança de rumos na carreira de Bilac, em direção à crônica, a partir do exílio em Ouro Preto provocado por Floriano. As ilusões perdidas de Euclides, que levam à descoberta do caminho de Canudos, podem também ser localizadas nesse mesmo ano. Em carta ao amigo Reinaldo Porchat, datada de 25 de novembro daquele ano, Euclides assim relata o seu malestar com a situação vigente, que acabará em desgosto com a farda e em sua reforma precoce, em 1896:

Depois de terminados aqui os trabalhos da Escola, irei com a Saninha até aí, passar um mês ou dois, talvez os de janeiro e fevereiro - e então conversaremos largamente e então talvez eu te diga tudo o que sinto, acerca de toda essa agitação, infecunda e anárquica, que por aí vai e pela qual um dia (pro pudor!), cego de entusiasmo, quebrei lanças... ${ }^{47}$

46. NABUCO. Minha formação, p. 70.

47. CUNHA. Correspondência, p. 52. Euclides naturalmente se refere, com amarga auto-ironia, ao episódio da revolta na Escola Militar, ocorrido em novembro de 1888, no qual vergou a lâmina da própria baioneta, a fim de quebrá-la diante do Ministro da Guerra, Tomás Coelho, e a ele se dirigiu com palavras injuriosas e profissão de fé republicana, motivo pelo qual foi desligado do exército. 
Nota-se, portanto, que o contexto em que Nabuco faz a sua exortação aos jovens escritores para que deixem de lado uma escrita frívola, em prol de uma meditação sobre a nação a partir de estudos históricos, constitui o mesmo contexto em que alguns dos jovens escritores republicanos encaram as suas decepções com as promessas frustradas do movimento de 1889, o que leva muitos deles a buscarem e encontrarem novos rumos para a própria escrita.

Nabuco não pode exercitar nas obras de imaginação o seu conceito de literatura contrário à eloquência, fosse na poesia ou na prosa, talvez por ter chegado tarde àquela formulação, como ele próprio disse. No entanto, Um estadista do império revela que a imaginação colocada ao serviço dos estudos históricos, como já mostrei através de Evaldo Cabral de Melo e de Raymundo Faoro, foi a sua forma de fugir da flâneurie de uma escrita sem valor.

Machado de Assis, em crônica publicada em 22 de março de 1895 na Gazeta de Notícias, aponta que Nabuco fazia reviver o passado através da biografia de seu pai, “... não à maneira seca das biografias de almanaque, mas pelo estilo dos ensaios ingleses." ${ }^{48}$ Machado vai ao centro da contribuição de Nabuco para as nossas letras ao usar a palavra "estilo" e ao denotar a relação entre estilo e eficiência narrativa. Não por acaso, Machado deveria simpatizar-se com o estilo do livro de Nabuco, uma vez que ele vinha da mesma tradição inglesa tão prezada pelo autor de Brás Cubas.

Cabe notar, no entanto, que a passagem entre a matriz eloquente de Hugo e o eficiente estilo inglês apontado por Machado não parece ter sido construída por Nabuco através de uma simples troca de fontes de emulação, e sim por um mergulho na realidade histórica e social brasileira, que o levou a constatar a necessidade de desenvolver uma escrita capaz de dar conta das nossas contradições. Sob esse ponto de vista, as considerações a que ele submete a própria escrita em Minha formação são como que um comentário que prepara a escrita de Um estadista do império. Meditando sobre o desenvolvimento da nossa estrutura política ao longo do império, nesse livro monumental, ou sobre o lugar da escravidão na nossa matriz social e econômica, em $O$ abolicionismo, escrito ainda na década anterior, Nabuco encontrou o tom pessoal e o estilo eficiente que antes buscava

48. ASSIS, Machado de. A Semana, 22.3.1895. In: NABUCO. Um estadista do império, p. 1287. 
na emulação de Renan ou de Chateubriand. ${ }^{49}$ A ele muito devem os nossos primeiros modernos na República Velha, entre eles Olavo Bilac e Euclides da Cunha.

Dessa maneira, o desenvolvimento do tema do estilo literário em Minha formação funciona como crítica ao estado da literatura entre nós num determinado contexto histórico, marcado pela eloquência e pela auditividade, ao mesmo tempo em que, como autocrítica, opera uma comentário metatextual sobre a evolução da escrita do próprio autor. A cem anos de sua morte, as considerações de Nabuco permanecem lúcidas e atuais, servindo de guia na compreensão daquela quadra de nossa cultura e de nossa literatura.

\section{Literature and style in Joaquim Nabuco's Minha formação}

Abstract: This paper investigates Joaquim Nabuco's literary concept, as he displays it in his book of memories, Minha formação. The analysis aims at two different goals: firstly, to describe the stylistic of Nabucos works, which is remarkably recognized to stand on clarity and interpretative efficiency; secondly, based upon his concept of literature, to investigate the trends of his literary generation, which ranks from late Romanticism to early Realism.

Keywords: Joaquim Nabuco, Memory, Literature, Style.

49. Evaldo Cabral de Melo aponta que Um estadista do império deve ser lido juntamente com $O$ abolicionismo, seu oposto complementar: "Há que se ler a biografia do pai contra o pano-de-fundo da crítica do filho ao regime escravocrata.". MELO. Um livro elitista?, p. 1324. 


$$
\text { Referências }
$$

BILAC, Olavo. Discurso no banquete em sua homenagem realizado no PalaceThéatre, 3 de outubro de 1907. In: MAGALHÃES JÚNIOR, Raimundo. Olavo Bilac e sua época. Rio de Janeiro: Editora Americana, 1974.

CARPEAUX, Oto Maria. Jacob Burckhardt: profeta da nossa época. In: A cinza do Purgatório. Rio de Janeiro: Casa do Estudante do Brasil, 1942.

CUNHA, Euclides da. Correspondência. GALVÃO, Walnice Nogueira; GALOTTI, Osvaldo. (Org.). São Paulo: EDUSP, 1997, 456 p.

FAORO. História e arte. In: NABUCO, Joaquim. Um estadista do império. 5. ed. Rio de Janeiro: Topbooks, v. 1, p. 21-30.

LIMA, Luiz Costa. Da existência precária: o sistema intelectual brasileiro. In: Dispersa demanda. Rio de Janeiro: Francisco Alves, 1981.

MELO, Evaldo Cabral de. Um livro elitista?. In: NABUCO, Joaquim. Um estadista do império. 5. ed. Rio de Janeiro: Topbooks, v. 2, p. 1321-1327.

NABUCO, Joaquim. Um estadista do império. 5. ed. Rio de Janeiro: Topbooks, 1997, 2 v.

NABUCO, Joaquim. Minha formação. São Paulo: Companhia Editora Nacional; Rio de Janeiro: Civilização Brasileira, 1934.

ROMERO, Sílvio. História da literatura brasileira. 7. ed. Rio de Janeiro: José Olímpio, 1980, 5 v.

SANTANA, José Carlos Barreto de. Ciência e arte: Euclides da Cunha e as ciências naturais. São Paulo: Hucitec, 2001, 214 p. 